\title{
De cómo una revista propone un modelo de cultura a un pueblo'
}

How magazine proposes a model of a people culture

\author{
Ddo. Jairo VALDERRAMA VALDERRAMA \\ Universidad de La Sabana (Colombia) \\ jairo.valderrama@unisabana.edu.co
}

\section{Resumen}

Es ya un lugar común, dentro de los estudios sobre cultura, afirmar que los medios masivos de comunicación tienen un impacto sobre la forma de conducirse y de pensar de los pueblos. Sin embargo, las investigaciones que pretenden mostrar cómo se da esa relación mediocultura en casos concretos son escasas, por lo menos en América Latina. Esta ponencia busca dar cuenta de algunos de los resultados de la investigación que se adelanta en el marco del Doctorado en Ciencias de la Comunicación de la Universidad Austral y cuyo objetivo central es dilucidar el modelo de cultura que propone un medio de comunicación colombiano de amplia difusión durante las tres últimas décadas del siglo XX.

El medio de comunicación es la revista Magazín Dominical (MD), del diario El Espectador $(E E)$, de Bogotá, elegido por su diversidad temática, la forma de usar los contenidos y su amplio impacto en la sociedad colombiana en un contexto político-social muy particular. Para su estudio, a partir del método de análisis de contenido, se establecieron varias categorías culturales que permitieron establecer el modelo de cultura implícito en la revista, sus

\footnotetext{
${ }^{1}$ Artículo producto de una Ponencia presentada en el VI Encuentro Panamericano de Comunicación COM PANAM 2013 celebrado la Escuela de Ciencias de la Información de la Universidad Nacional de Córdoba (Argentina), durante los días 5, 6 y 7 de junio de 2013.
} 
características temáticas, la frecuencia y la orientación liberal. Esas categorías son: el pensamiento crítico y el debate, la participación abierta a sectores populares, el cuestionamiento institucional, la inquietud social, la visión de mundo, el papel del hombre en el mundo y la revisión histórica. Por su puesto, su selección no es fruto del azar, sino de la revisión textual y de las apreciaciones del equipo editorial que conformó la revista durante un periodo coyuntural de Colombia. Sus miembros publicaron luego, en 1997, un compendio en tres volúmenes, fruto de un trabajo detallado de selección, que demuestra la universalidad y vigencia de los contenidos.

Esta ponencia cuenta con tres momentos básicos. Inicialmente, se expondrá el marco general de la investigación: la relevancia del Magazín Dominical y el método de Análisis de Contenido. En un segundo momento, se explicará cómo se aplicó el método a las categorías culturales diseñadas y cómo se cristaliza un modelo de cultura en el Magazín Dominical. Finalmente, se mostrará cómo este procedimiento es aplicable a otras investigaciones similares y redunda en beneficio de una comprensión más detallada de la relación inextricable entre medios masivos de comunicación y cultura; una comprensión que tal vez permita apreciar desde otra óptica que el mundo humano no es más que una urdimbre infinita de símbolos. Como lo asegurara Foucault de Don Quijote:

Don Quijote ha tomado su realidad. Realidad que sólo debe al lenguaje y que permanece por completo en el interior de las palabras. La verdad de Don Quijote no está en la relación de las palabras con el mundo, sino en esta tenue y constante relación que las marcas verbales tejen entre ellas mismas. 2

\section{Summary}

${ }^{2}$ Foucault, Michel. Las palabras y las cosas, una arqueología de las ciencias humanas. Buenos Aires: Siglo Veintiuno Editores, 1968. 
It is now commonplace within culture studies assert that the mass media has an impact on the way of behaving and thinking of the people. However, research purporting to show how the medium -culture relationship is given in specific cases are rare, at least in Latin America. This paper seeks to explain some of the results of the investigation conducted under the PhD in Communication Sciences from the Universidad Austral and whose main objective is to elucidate the cultural model that proposes a media Colombian widely during the last three decades of the twentieth century.

The communication medium is the magazine Sunday Magazine (MD), the daily El Espectador ( EE), Bogota, chosen for its thematic diversity, how to use the contents and its broad impact on Colombian society in a political - social context very particular. For their study, from the method of content analysis, several cultural categories for drawing up the model implicit culture magazine, theme features, frequency and liberal orientation were established. These categories are: critical thinking and debate, open to grassroots participation, institutional questioning, social unrest, the worldview, the role of man in the world and the historical review. Of course, your selection is not random, but the textual review and the findings of the editorial team that shaped the magazine during a cyclical period of Colombia. Its members then published in 1997 a collection in three volumes, which results from a detailed selection, demonstrating the universality and validity of the content.

This paper has three basic moments. Initially, the general framework of the research will be discussed : the importance of the Sunday Magazine and the method of content analysis. In a second step, the method will be explained how the cultural categories designed and applied a model of how culture is crystallized in the Sunday Magazine. Finally, we show how this procedure is applicable to other similar research and the benefit of a more detailed understanding of the inextricable relationship between mass media and culture, an understanding that perhaps allowing assessment from another perspective that the human world is not rather than an infinite warp symbols. As Foucault ensure Don Quijote: 
Don Quijote has taken its reality. Reality only due to language and remains completely within the words. The truth of Don Quixote is not in the relation of words to the world, but in this dim and constant relationship between verbal brands weave themselves.

Palabras Clave: cultura, medios de comunicación, pensamiento crítico, participación, cuestionamiento institucional, inquietud social, cosmovisión.

Key Words: Culture, media, critical thinking, participation, institutional questioning, social unrest, worldview.

\section{Introducción}

\section{El objeto de estudio y la metodología}

Separata del diario El Espectador, el Magazín Dominical (MD) representó los ideales de ese periódico liberal y, en particular, de la familia dueña del periódico, los Cano; de hecho, su directora más insigne fue Marisol Cano Busquets. El impacto social y cultural fue tal que se utilizaba el Magazín como herramienta pedagógica en las escuelas más alejadas del centro del país; había tertulias en las universidades para discutir su contenido; existían coleccionistas del MD que ofrecían cambiar los números repetidos. Esa pequeña revista, de 20,5 cm por $27 \mathrm{~cm}$. y encuadernada en 24 páginas, estaba aportando a la cultura del país, invitaba a observar otras perspectivas de la realidad, a pensar de manera diferente. Teníamos a la mano un cuento inédito de Borges, un poema de Rimbaud; nos enterábamos de un festival de teatro en Manizales; sufríamos con las masacres del Urabá antioqueño o el clamor de las Madres de Mayo; se pensaba en Foucault o en las canciones de Sabina. Ahora, con las herramientas de un comunicador social, nos preguntamos ¿qué hizo el Magazín en ese entonces?, ¿cómo lo hizo? 
La cultura no es sólo la acumulación de información en los libros, ni de datos en los cerebros, ni estatuas de museos. El Magazín supo que para llamarse "cultural" debía abarcar el espíritu mismo de lo humano. Por eso, la cultura, como concepto, no se agota en sus determinaciones académicas (primera dificultad de esta investigación): qué organiza una población; qué son los símbolos de una comunidad; qué produce el hombre; que es el conocimiento acumulado de un pueblo; qué son las costumbres; qué es, qué es, qué es... Sí, todo eso es cultura, pero también mucho más. Ante el requerimiento académico y operativo de un concepto de cultura, optamos por el más general, siempre con la salvedad de que no es ni puede ser definitivo.

Por una parte, en un sentido amplio, la cultura es el conjunto de actividades y constructos propiamente humanos que lo distinguen y separan de la naturaleza. Así, pues, todo lo humano es, en sentido estricto, cultural: los elementos simbólicos (como el lenguaje, las normas, las creencias, los saberes); los constructos materiales (como las herramientas y los adornos); ya sean actividades o productos, son cultura. Además, tienen la función fundamental de garantizar la supervivencia humana física (la técnica y sus herramientas) y orientar su conducta hacia la satisfacción de sus necesidades, sean estas físicas, intelectuales, psicológicas o morales (como el arte, la religión o el derecho).

Por otra parte, en un sentido restringido ( $\mathrm{y}$ en esto se toma como punto de partida la definición de la UNESCO, citada por Cacua. [Cacua P.: 1993, p. 22] ${ }^{3}$, puede hablarse de la cultura como el conjunto de rasgos distintivos, simbólicos y materiales, intelectuales y afectivos, (creencias, costumbres, producciones artísticas y cognitivas, sistemas normativos, tradiciones y modos de vida) que caracterizan a una sociedad o a un grupo social en particular.

${ }^{3}$ En TROYANO, H. (ed.) (1993). Periodismo cultural y cultura del periodismo. Secretaría Ejecutiva del Convenio Andrés Bello y Fundación Konrad Adenauer. Bogotá D. C. 
A partir de acá, se trató de dilucidar el modelo de cultura que el Magazín proponía desde el contenido y la forma de sus notas, de sus artículos: en palabras anteriores, ¿qué hizo el Magazín? Había que llegar a los elementos subyacentes que reflejaran un modelo de cultura en particular, si es que esto existe.

La herramienta fue el Análisis de Contenido ( $A C)$, que, según Berelson, es "una técnica de investigación para la descripción objetiva, sistemática y cuantitativa del contenido manifiesto de la comunicación" (1952: 18). Por su puesto, la "objetividad" se refiere a procedimientos que puedan ser utilizados por otros investigadores, que los resultados obtenidos sean susceptibles de verificación; la "sistematización" hace referencia a pautas ordenadas que abarquen el total del contenido observado (Andréu, 1998).

Sin embargo, ese "contenido manifiesto", como lo llama Berelson, resulta aquí muy fácil de determinar; porque el propósito central de esta investigación es indagar acerca de una propuesta cultural, de comprender las comunicaciones más allá de sus primeras significaciones y superar la incertidumbre acerca de si una percepción primera o latente también puede ser percibida o creída por otros atentos lectores; se buscan inferencias mayores. Dos son las recomendaciones: "la verificación prudente y la interpretación brillante" (Bardin, 2002: 21 y 22).

Hay otro sentido, latente, "indirecto, que se sirve del texto manifiesto como de un instrumento, para expresar el sentido oculto que el autor pretende transmitir". (Andréu, 1998: 2). El $A C$ se soporta, sobre todo, en la inferencia para reflexionar sobre el contexto social donde se produce el texto. Aparte de exponer en un primer paso qué se dijo (el sentido manifiesto), debe llegarse a la intención última de buscar fuera del texto, pues las dimensiones de los datos extraídos del análisis sólo existen fuera de los "continentes", es decir, en la mente de los sujetos productores o usuarios de los mensajes, textos, discursos, o documentos que se analizan (Piñuel, 2002: 3). 
Por su puesto, las representaciones sociales y previas del investigador enmarcan las inferencias y, sobre todo, referidas a las intenciones, creencias, posiciones y estados mentales del interlocutor (Piñuel, 2002: 6). Por ello, se ha de considerar como válida la inferencia si también se apoya para su argumentación en los esquemas socialmente establecidos, porque el $A C$ es una investigación empírica, destinada a estudiar los contenidos recurrentes de una determinada muestra de texto (Casetti y Di Chio, 1999: 235); se trata de hallar la carga de significado, codificar los diversos elementos de un mensaje en categorías con el fin de hacer aparecer de manera adecuada su sentido"4 (Mayer y Quelle, 1991: 473).

El francés Laurence Bardin, uno de los autores más consultados en esta materia, sintetiza la definición del Análisis de Contenido de la siguiente manera:

Un conjunto de técnicas de análisis de comunicaciones tendente a obtener indicadores (cuantitativos o no) por procedimientos sistemáticos y objetivos de descripción de contenidos de los mensajes permitiendo la inferencia de conocimientos relativos a las condiciones de producción/recepción (variables inferidas) de estos mensajes (2002: 32).

La mayoría de autores coinciden en que es "un método que busca descubrir la significación de un mensaje... una historia de vida, una artículo de revista...un decreto ministerial, etc." (Gómez M., M. A., 2000, 2).

Así, pues, el procedimiento para aplicar el $A C$ al $M D$ lo proponen Francesco Casetti y Federico Di Chiuo (1999: 236-244): 1. Definición del problema y formulación de hipótesis; 2. Elección del corpus; 3. Definición de las unidades de clasificación; 4. Preparación de la ficha de análisis; 5. Computación de resultados.

Por encima de los detalles metodológicos, que son comunes a muchas investigaciones, nos interesa resaltar aquí las categorías seleccionadas, casi que inventadas, para agrupar la

${ }^{4}$ Con algunas pequeñas variantes, esta misma definición la plantea Miguel Ángel Gómez Mendoza (2000: 2). 
diversidad temática del Magazín y facilitar la posterior deducción del modelo de cultura propuesto por la revista.

La muestra seleccionada para este análisis es Memoria Impresa, Antología del Magazín Dominical de El Espectador, un libro en tres volúmenes que es el resultado de la selección de notas publicadas en el Magazín Dominical durante diez años (1983-1993). La selección fue realizada directamente por tres de los directores de la revista: Arcila, Cano y Roca. La muestra es representativa por esas dos razones: porque son diez años clave en la vida del Magazín y porque quienes llevaron a cabo la selección fueron, en su momento, los que lideraron el proceso de construcción de la revista.

Producto del análisis sistemático de la muestra y de diversos estudios de cultura, surge una serie de categorías que engloban una tendencia en el $M D$, pero que, como se verá, pueden ser extensivas a otros medios o a otros textos, cuando pretende indagarse por la cultura. Esas categorías son las siguientes:

\section{Resultados}

\subsection{El pensamiento crítico y el debate (PCD).}

Esta categoría incluye aquellos artículos o notas que de manera explícita o implícita son críticos del statu quo o que, por la forma en que abordan determinados temas, suscitan la crítica. Por su puesto, si la crítica está sustentada, ella misma es debate, polémica, confrontación. Esta categoría se conforma, entre otras cosas, porque, promover un pensamiento crítico formaba parte de los objetivos fundamentales y explícitos de la revista, como lo confirma este aparte del prólogo de Memoria Impresa:

Debemos decir, muy a nuestro pesar, que el intelectual colombiano se ha vuelto de una asombrosa acriticidad, renuente al debate de ideas, a tal punto que el mismo medio ya estigmatiza, macartiza, señala como bichos raros a quienes se atreven a pendular la 
cabeza con el signo de no, a quienes se atreven al disentimiento (Arcila, Cano y Roca, 1997:6)

Cuando exponía los motivos que guiaban su trabajo mientras estuvo vinculado al MD desde finales de los años 70, Guillermo González Uribe aclaraba que "era como buscar pensamiento crítico y creación... siempre", entre los lectores (2011).

\subsection{La participación abierta de los sectores populares (PAP)}

Esta categoría integra a emisores, receptores, canales y medios de todo el país para tratar de llegar con sus mensajes a lugares distantes. Así lo confirma Roca: "se incluyó la cultura popular; no queríamos una publicación elitista. Al principio hubo resistencia, porque se creía que era una cosa populista” (Roca, J. M. 2012). ¿Cuál es la delimitación entre lo popular y lo elitista? ¿El calificativo de "popular" no es ya un reconocimiento a la primacía de la cultura hegemónica?

\subsection{Una revisión histórica $(\mathrm{RH})$}

Esta categoría incluye las temáticas que abordan de manera explícita o implícita la Historia, para cuestionarla, para mirar lo que otros habían querido ver o nos habían querido hacer ver. La historia tradicional, sobre todo la colombiana, está oficializada para justificar su presencia y sus acciones en un pasado histórico-mítico. El Magazín sentó su posición: se buscaba "...que todo el material fuera producto de la investigación: causas, consecuencias, fuentes, antecedentes" (González U. G. 2011). Los modelos de los historiadores, reiterados durante muchos años en casi todos los centros de educación en Colombia, llevó a que el MD también presentara, con mayor equilibrio, distintas versiones al respecto: "Inclusive, armamos un debate acerca del tipo de historia que se estaba enseñando en Colombia. Sentamos a los historiadores y debatimos... (Cano, M. 2012). 


\subsection{El cuestionamiento institucional (Cl)}

Aunque cabrían las anteriores categorías, se pensó en esta para considerar el accionar de los grupos oficiales de control, sobre todo cuando no hay garantías estatales para defender la libertad de prensa, o los mismos representantes del gobierno la atacan:

Por ejemplo, un Magazín que era con textos e imágenes de gente que había desaparecido. Y salió al día siguiente un comandante de las fuerzas militares a decir que eso era un Magazín subversivo, que eso eran calumnias y mentiras, y Guillermo Cano salió al otro día con un editorial a apoyarnos (González U., G. 2011).

Guillermo González Uribe recibió una carta de una estudiante, previniéndolo del riesgo de permanecer en Colombia: "Te quiero decir que estuve en una reunión de gente de derecha, y se hizo un lista de periodistas para matarlos, y tú estás en esa lista..." (2011). Él salió del país y se asiló en España con el apoyo de su familia.

Las versiones de Marisol Cano Busquets enmarcan las distintas reacciones que generaban esos contenidos: "Muchos dijeron que éramos una avanzada de las FARC5 y de la guerrilla en Colombia" (2012).

Pero la crítica a la institucionalidad, también incluye a los medios, que actúan como justificadores o desinformadores de las acciones estatales, con la superficialidad y la estandarización. Están de acuerdo en las intenciones rentables, y desde esta inclinación deciden los contenidos:

Se vive la tendencia más triste del periodismo cultural. Ahora es espectáculo y entretenimiento: importan la figura, el estatus; la banalización del periodismo. Hay mucho miedo a la profundidad. Pasa lo que pasa por la primera capa de trabajo o de lectura; es vergonzoso; se cierran espacios muy grandes (Cano M. 2012).

\footnotetext{
${ }^{5}$ Este grupo guerrillero se autodenomina "Fuerzas Armadas Revolucionarias de Colombia. Ejército Popular" (FARC-EP) (N. del A.).
} 
Juan Manuel Roca Vidales señala parte de la crisis del periodismo: "el problema ahora con los periódicos es que ya no los dirigen los periodistas, sino la gente de mercadeo, que son una raza de mutantes, absolutamente hueca, calcárea" (2012).

\subsection{La inquietud social (IS)}

Esta categoría se centra en las problemáticas sociales constantes y no sólo coyunturales. "Se estaba al día en asuntos de interés nacional: DD. HH., desplazados, etc. Publicamos lo que no publican los medios [habitualmente]..." (Roca, 2012).

La IS propende por elementos adecuados y suficientes de juicio para tomar decisiones; se consideran las instituciones educativas o entes que incidan en la formación de opiniones con efectos sociales, por ejemplo los medios, que "buscan el reemplazo de la cultura por el espectáculo. Hasta el punto de llegar a una "shakirización”6 de la cultura (Roca, J. M. 2012).

\subsection{Visión de mundo (VM)}

Con ella se explican modelos distintos al de la propia cultura, que parten de los medios, la familia, la escuela (en su acepción genérica) para crear sólo un ambiente nacional o local. En el $M D$, se buscaron otros argumentos y representaciones para cuestionar las mismas manifestaciones, pero expuestas en otros contextos. "Nuestros medios tienen un discurso, y el contenido es muy igual, muy empobrecido... Se reciclan los temas y la manera de verlos. (Cano M., 2012). Se trata de descubrir si existe más de un "paradigma" (o, por lo menos, unificado), tomando como fundamento un sistema de creencias, de acuerdo con la posición de Thomas Kuhn (2005).

\footnotetext{
${ }^{6}$ El poeta Juan Manuel Roca Vidales alude a la famosa cantante colombiana Shakira para referirse a cómo el espectáculo popular, la información personal de los famosos y la farándula se mostraba como cultura, sin que esta lo fuera. (N. del A.).
} 


\subsection{El hombre en el mundo (HM).}

Aquí se analizan las profundidades de la conciencia humana: traumas, debilidades propias de nuestra especie, los secretos que todos llevan dentro, anhelos, sueños, tragedias, fracasos, todas como formas de vivir que se han establecido en el mundo.

\section{Discusión}

\section{Cómo cristalizar un concepto de cultura}

El modelo de cultura toma alguna consistencia cuando las categorías prolongan sus brazos para enlazarse con las otras, en un tejido que prueba su consistencia en los indicios del $M D$, porque, en alternadas visiones, se describen y narran las condiciones que afronta la sociedad colombiana y, en casi todos los casos, se expone las causas.

Al buscar las inferencias para el pensamiento crítico y el debate $(P C D)$, estas flotan por sí solas en las páginas del $M D$ como si buscarán el oxígeno vital que no encuentran estando sumergidas. Muchas páginas tratan la falta del hábito de la lectura, uno de las más esenciales para formar un criterio fundamentado. En el caso del papel de la literatura, por ejemplo, se sustentan los argumentos, y "deja de ser una cuestión estética" cuando se convierte en "un insoportable ejemplo de pusilanimidad y gregarismo" (vol. 1, p. 39); es decir, las doctrinas y los dogmas llevan a que "muchos alfabetos confundan el sermón, enmarcado en el incienso, con el uso modesto de la facultad de pensar (vol. 1, p.169). A la gente parece que le faltara la iniciativa; da la impresión de que quisiera un manual para fijar allí sus opiniones y su diario proceder.

El filósofo Rubén Sierra Mejía, refiriéndose a la filosofía (es decir, a ese amor por el pensamiento fundamentado), dice que en Latinoamérica el proceso del pensamiento, de razonar, de someter a juicios, no depende de las distinciones de una comunidad con respecto a otra. "Se pretende una originalidad de pensamiento, creyendo que ella se logra a 
través de un determinado campo de problemas definidos por su localismo geográfico y no más bien de un sistema conceptual y metodológico, solo a partir del cual se lograría la identificación de las propiedades características de un pensamiento filosófico" (vol. 2, p. 149).

Sin embargo, de nada valen estos esfuerzos si los canales están taponados: "hay intelectuales muy capaces, pero no tiene acceso a los medios para un debate público" (vol. 2, p. 170); se requiere "que la opinión sea pública" (vol. 2, p. 285). Ante este reto, el $M D$ reitera que "el intelectual crítico, empezando por Sócrates, ha tenido siempre un enemigo: el poder" (vol. 2, p. 286); el MD refuerza la idea de que la libertad es imprescindible, y el engaño no es su mejor aliado. "Todo parasitismo es explotación y por ello es condenable... El hombre que no es libre, entorpece la libertad de los otros. La libertad será colectiva o no existirá jamás" (vol. 2, p. 291).

Con la Participación Abierta de Sectores Populares (PAP), el MD pisa fuerte con un título que dice: "la cultura es asunto de todos" (vol. 3, p. 155), pero decisiones como esa no las toman todos y no las disponen para todos: "la bomba atómica jamás fue sometida a voto" (vol. 2, p. 157), y, aparte de ello, hasta el acceso a la formación cultural la "concentramos en... grandes ciudades", donde está "la mayoría de teatros...museos y orquestas. Y fuera... quedaron los destituidos y excluidos" (vol. 2, p. 159). Las manifestaciones de un pueblo y el acceso para descubrir las de otros están restringidas desde que "la democracia griega fue derrumbada por los militares... y sustituida por la cultura de élite" (vol. 2 p. 157). Por ello ha surgido la confusión de que el arte se enfoca para la llamada "gente culta" y excluye la "alegría del subdesarrollo". (vol. 3, p. 65).

En las consultas al pasado, en el $M D$ aparece la voz del escritor mexicano Carlos Fuentes: "No creer que nuestra cara es una cara progresista, occidental, perfecta, sino... una cara india, mestiza, criolla" (vol. 1, p. 147), para indicar que nuestros genes no provienen de cabellos rubios y ojos azules de los comerciales, donde se falsea la naturaleza. Los medios sustituyeron la historia por la leyenda, por ejemplo cuando se le hizo creer a la mayor parte 
del mundo que las únicas opciones eran el capitalismo o el comunismo... "esto creó una congelación de pluralidad de las culturas" (vol. 1, p. 148).

Por ello, el $M D$ cuestiona las instituciones y la validez de sus propuestas, que propagan una única percepción del mundo. En Colombia, por citar el ámbito más cercano, no puede cuestionarse, dice el escritor Eduardo García Aguilar: "Para mí vivir en Colombia sería un martirio, pues la única respuesta que dan a quienes protestan o piden justicia es en el lenguaje de las ametralladoras" (vol. 1, p. 34).

La dependencia de identidad nacional también se descubre y se desplaza, en otra proporción, en las maneras de vivir de las subculturas excluidas, que también son cultura, porque "hay un desarrollo social que impide que la gente consuma cultura (vol. 1, p. 129). Las otras versiones deben estar en manos del intelectual, y este "tiene [...] un papel que cumplir y su arma o instrumento es la lucidez" (vol. 1, p. 42). El progreso de toda persona se refuerza, citando a Nietzsche, con el cambio ante las circunstancias: "La serpiente que no logra mudar de piel perece, así como las almas que no saben mudar de opinión dejan de ser almas" (Vol. 1, p. 51).

El escritor mexicano Carlos Fuentes recomienda: "No casarse con ningún dogma, con ninguna idea fija; mantener la mente alerta y fluida, como requiere el debate con uno mismo, el cuestionarse..." (vol. 1, p. 144). El MD recuerda que en los Estados Unidos se prohibía que los esclavos aprendieran a leer (vol. 1, 162), que la derecha infundía el racismo y antisemitismo (vol. 1, p. 163), que el anticomunismo fue el pretexto para suprimir la disidencia (vol. 1, p. 164); se encajaba al hombre en "el provincianismo, [que] es la ignorancia de los demás", dice el escritor colombiano Óscar Collazos (vol. 1, p. 183).

Sin embargo, para hallar esos faros que permiten ubicarnos en el mundo, muchos hombres van detrás de las luciérnagas, porque la simulación y la apariencia confunden, y muchas versiones propagadas se toman como la "verdad". Esta idea es reiterada a lo largo de muchas páginas del $M D$ : "El peor enemigo de algo es lo que se le parece: la coquetería, al 
amor; lo bonito, a la belleza; la diplomacia, a la política..." (vol. 2, p. 40). Cuántas intenciones de la felicidad de un hombre se truncan porque "los peligrosos, los insensibles, los insensatos códigos de la civilización lo pisotearían" (vol. 1, p. 90).

No obstante, aparecen atenuantes para aligerar el peso de la realidad, como la opinión del escritor Ernesto Sábato, hablando de "las supersticiones [...]; tienen un valor catártico y salvador de la especie humana $[\ldots]$, pero no en esa literatura que sirve a fines propagandísticos para una iglesia o para un partido" (vol. 1, p. 121), porque el hombre no debe ser encasillado en el mundo; "las creencias aglutinan a las masas en el consumo y el materialismo... Hechizan con la tecnología usurpándoles la posibilidad de crear una cultura activa, para sumirlas en el confort y estupidez de la cultura pasiva" (vol. 2, p. 35).

En la misión de vida, que debe ser alguna, cada hombre debiera representar su propio y auténtico papel, sobre todo si está dotado para ello, no como "el actor sometido a la codificación del oficio" (vol. 2, p. 44); "cada quien tiene derecho a hacer de su vida lo que quiera, aunque los demás nunca entiendan" (vol. 1, p. 75). A pesar de que cambien algunos espacios o momentos para situar las emociones humanas, no por ello estas son diferentes: "El amor no es más grande ni más profundo, ni más cierto porque, en vez de hacerlo en la alcoba", se haga en el estudio (vol. 2, p. 41). Esa conciencia, aproximada por lo menos, de que muchas palabras y acciones propenden por el mal o por el bien se constituye en la defensa de la autonomía: "Solo si uno tiene valores muy fuertes, puede existir en un mundo como el actual, que destruye al individuo" (vol. 2, p. 56). Desde otras épocas, el MD recuerda cómo Cyrano de Bergerac y su grupo de seguidores abrían las brechas entre la superstición y las nuevas ideas, para plantear que la amnesia del mundo, como paradoja, puede extinguirse con la fantasía:

Salvados de la proscripción o de la hoguera, estos campeones de la razón se volvieron cautelosos ante toda dictadura espiritual, y hubieron de disfrazar sus pensamientos, sus descubrimientos, sus nuevos sueños, sus intuiciones, mediante sutiles imposturas que a 
veces denominaban conversaciones... Si el martillo inquisidor sospechaba de ellos, se podía argüir que aquello era ficción, juego de la imaginación... (vol. 1, p. 215).

En el MD se plantea la libertad como garantía de la expresión auténtica del ser humano, con una misma repercusión para todas las voces. Si plantea tal demanda, es porque, para esta revista, no existe esa garantía en la cultura que describe. Y se reconoce que "Colombia es un país cuyos puntos cardinales siempre limitan con el olvido. Pareciera que la historia nuestra fuera escrita más por el lado del borrador que por la punta del lápiz" (vol. 1, p. 53).

\section{Conclusión}

Este método, como cualquier otro recurso investigativo de este tipo, exige disponerlo de forma adecuada. El $A C$ ha de seguirse por razones de practicidad y porque la secuencia que establece corresponde a una lógica en el proceso, donde se verifica que solo atendiendo a un orden podrá llegarse al objetivo señalado.

Los contenidos mediáticos, con el fin de ganar mayor audiencia, parecen cambiar. Sin embargo, apenas se modifican las apariencias en muchas transmisiones, pero el fondo de significado permanece; este es un indicio de que la cultura (el pensar y el actuar) tiende a ser realimentada por los medios masivos. Frente a estos, la audiencia confunde diversidad (ofertas distintas culturales) y variedad (variantes del mismo producto) (McQuail: 1998, 262). En el MD se notan propuestas distintas.

Las categorías establecidas en esta investigación, en esencia, podrán ser las mismas para otras investigaciones, aunque los nombres cambien. Con el referente de la pesquisa histórica de las revistas llamadas culturales y de las características comunes de estas en Occidente, es muy factible que estos campos de abordaje sean aplicables en muchos otros casos si se quiere contar con una aproximación al modelo de cultura que se le ofrece a un pueblo. 


\section{Bibliografía}

ANDRÉU, J. (1998) . Los españoles: Opinión sobre sí mismo, España y el Mundo. Análisis Longitudinal Escala de Cantril. Ed. Universidad de Granada.

ARCILA, C. A.; CANO, M.; ROCA, J. M. (compiladores) (1997). Memoria Impresa. Antología del Magazín Dominical de El Espectador. Volúmenes 1, 2 y 3. Editorial Universidad de Antioquia. Medellín.

BARDIN, L. (2002): Análisis de contenido. Ediciones Akal, Madrid.

BERELSON, B. (1952). Content Analysis in Comunication Research, Free Press, Glencoe.

CASETTI, F.; y DI CHIO, F. (1999). Análisis de la televisión. Instrumentos, métodos y prácticas de investigación, $1^{\text {a }}$ Edición, Barcelona, Paidós. Traducción de Charo Lacalle Zalzuendo.

CANO, M. (2012). Entrevista. Barcelona-Bogotá. Vía skype. 4 de octubre.

GÓMEZ M., M. Á. (2000). Análisis de contenido cualitativo y cuantitativo: definición, clasificación y metodología. En Revista de Ciencias Humanas, No 20. Universidad Tecnológica de Pereira. Pereira, Colombia.

GONZÁLEZ U., G. (2011). Entrevista, Bogotá, septiembre.

KUHN, T. (2005). La estructura de las revoluciones científicas. Fondo de Cultura Económica de España. Madrid.

MAYER, R. y QUELLET, F. (1991). Méthodologie de recherche pour les interventants sociaux. Boucherville. Gäetan Morin Editeur. Montreal-Paris-Casablanca. p. 473-502.

MAGAZÍN DOMINICAL. En el diario El Espectador, Bogotá.

McQUAIL, D. (1998). La acción de los medios. Los medios de comunicación y el interés público. Amorrortu Editores. Buenos Aires. 
MUÑOZ C., A. (2002). Presentación, En Análisis de contenido, de Laurence Bardin. Ediciones Akal. Madrid.

PIÑUEL R., J. L. (2002). Epistemología, metodología y técnicas del análisis de contenido, en Estudios de Sociolingüística 3. Departamento de Sociología IV. Facultad de Ciencias de la Información. Universidad Complutense de Madrid. Madrid.

ROCA V., J. M. (2012). Entrevista. Bogotá, 16 de septiembre.

TROYANO, H. (ed.) (1993). Periodismo cultural y cultura del periodismo. Secretaría Ejecutiva del Convenio Andrés Bello y Fundación Konrad Adenauer. Bogotá.

\section{Forma de citar este artículo en bibliografías}

VALDERRAMA VALDERRAMA, J. (2013): "De cómo una revista propone un modelo de cultura a un pueblo", en Revista PANGEA, 4, páginas 307 a 324. Red Académica Iberoamericana de Comunicación. Recuperado el __ de ___ de 2 __ de: http://revistapangea.org 